\title{
Dylan Thomas, el hijo de la ola: una aproximación a su poesía temprana
}

Ana Elena GonZÁLEZ TREVIÑo

Universidad Nacional Autónoma de México

\begin{abstract}
Este artículo ubica la poesía de Dylan Thomas en el contexto literario y cultural de la década de los treintas, entonces dominado por Yeats, Eliot y Auden. Se describe la recepción de 18 Poems y la participación de Thomas en la gran exposición surrealista de 1936. Dado el talento de Thomas no sólo para escribir sino también para hacer lecturas públicas de su poesía, se destacan los aspectos sonoros que rigen sus composiciones. Finalmente, se analizan ejemplos de tres temas que permean la poesía temprana de este autor galés: los sueños de génesis, la labor del poeta y el ciclo vital.
\end{abstract}

PALABRAS ClaVE: Dylan Thomas, poesía moderna, surrealismo, poesía galesa, cynghanedd

This article places the poetry of Dylan Thomas within the literary and cultural context of the 1930s, then dominated by Yeats, Eliot and Auden. It describes the reception of 18 Poems and Thomas's participation in the great surrealist exhibition of 1936. Given Thomas's talent not only to write but also to make public readings of his poetry, it underscores the sonorous aspects around which his compositions are built. Finally, it analyzes examples of three main themes which permeate the early poetry of this Welsh poet: dreams of genesis, the task of the poet and the vital cycle.

KEY WORDS: Dylan Thomas, modem poetry, surrealism, Welsh poetry, cynghanedd.

Yeats, Eliot y Auden forman la tríada de poetas intelectuales que dominaba el panorama poético inglés cuando Dylan Thomas acababa de llegar a Londres de Gales en 1935, a los veinte años de edad. En aquel año, Yeats había cumplido ya setenta años y veía la publicación de The Winding Stair con la tranquilidad que da la reputación establecida. Arduo luchador social, hacía poesía sobre el presente basándose en los mitos celtas, en la Biblia, en el esoterismo y, de manera particular, en la poesía de William Blake. T. S. Eliot, a sus cuarenta y seis años, acababa de publicar el primero de sus Four Quartets y gozaba de una gran autoridad en el medio. Los poetas de Oxford, encabezados por W. H. Auden reflejaban en su poesía una preocupación sociológica, a menudo socialista, desarrollada también con gran complejidad intelectual. La popu- 
laridad del libro Poems de Auden lo había convertido en una especie de héroe socialista a los veintisiete años de edad. El público de la poesía inglesa de los años treintas estaba entonces habituado a los temas de la mitología, la antropología y la política.

Es por esta razón que los 18 Poems de Dylan Thomas (publicados en Londres en diciembre de 1934) irrumpen en el ámbito poético desconcertando a la crítica y al público. Su extraño vigor no pasó inadvertido, aunque parecía no embonar en ninguno de los escaños existentes. Hubo varias reseñas favorables en distintos diarios. Thomas había conseguido llamar la atención para hacerse un lugar en el panorama literario del momento. Desmond Hawkins publicó una memorable reseña del libro en el semanario Time and Tide que le abrió las puertas de Londres al joven Thomas (Ferris, 1978: 122). Llamaba la atención la pasión con la cual expresa la verdad paradójica del ciclo vital en "The Force That through the Green Fuse Drives the Flower" o la cualidad visionaria de "In the Beginning" o la sugerente rareza de "I Fellowed Sleep".

El único poeta contemporáneo que a primera vista parecía tener algo en común con Thomas era D. H. Lawrence, fallecido en 1930. Lawrence, mejor conocido como novelista, no formaba parte del grupo de poetas oficiales, pero introdujo en la poesía vocablos e imágenes de gran sensualidad que no se habían visto antes. Sin embargo, Thomas mismo lo descartaba como influencia por sus tendencias paganas, pues su propia poesía está impregnada del lenguaje y los mitos cristianos. Aun así, en la importancia que ambos le daban al aspecto sonoro, es innegable la afinidad con D. H. Lawrence (Burdette, 1972: 152).

Resulta interesante entonces que Eliot elogiara "Light Breaks Where No Sun Shines" y "Our Eunuch Dreams", y que Stephen Spender, perteneciente al grupo de Auden, organizara una de tantas colectas en su beneficio, además de ser el crítico más benévolo de los Collected Poems de 1951 (Ferris, 1978: 102). Aquí debemos aclarar que Thomas tenía una desventaja cultural insoslayable que es el arraigado prejuicio que existe entre los ingleses hacia el país de Gales y todo lo galés. Thomas, a quien incluso hoy en día se considera el principal poeta galés de los últimos tiempos, irrumpe en el ámbito inglés en busca de reconocimiento, sí, pero se presenta como un galés de pura cepa. Si a esto añadimos su alcoholismo y su conducta excéntrica y escandalosa, la apreciación se complica aún más. Lo notable es que a pesar de todas estas cosas, Thomas logró de alguna manera labrarse un lugar permanente en el Parnaso inglés, a través de poemas verdaderamente inolvidables.

En 1936, Dylan Thomas leyó su obra en la gran exposición surrealista de Londres que se llevó a cabo en las Nuevas Galerías Burlington. Al evento acudieron figuras de la talla de André Breton, Paul Eluard, Man Ray y Salvador Dalí, quien dio una conferencia inaudible disfrazado de buzo y con la boca cubierta, aunque por poco se asfixia porque se le atascó el casco $^{1}$ (Pratt, 1970: 130). Con el pretexto de su participación,

\footnotetext{
Se dice que más tarde Dylan Thomas se paseó por la exposición ofreciendo a los asistentes tazas de cordones hervidos. Ver http://www.manchesterconfidential. co. uk/Culture/Architecture/Albert-Squareand-the-Surrealist-Phantom_4053.asp
} 
no faltó quien comenzara a llamar a Thomas poeta surrealista. Esta etiqueta parecía la explicación perfecta para las partes incomprensibles de sus poemas, la carencia de lógica y la sobresaturación de imágenes. Sin embargo, aunque Thomas sí realizó experimentos de escritura automática, jamás aceptó esta clasificación. Rechazaba la idea de que escribir poesía fuera un acto inconsciente. Todo lo contrario. Afirmaba que se requería todo el esfuerzo y la concentración del poeta, además de numerosas revisiones, para poder llevar a cabo la labor del poeta (Ferris, 1978: 134). Además, Thomas estaba decepcionado del surrealismo porque predicaba la decadencia de la realidad y el dominio del caos. Su postura resulta interesante en la medida en que su poesía, considerada oscura por muchos, es finalmente una poesía enaltecedora, que celebra la luz y la vida.

En lo personal, Thomas se alineaba con William Blake, a poco tiempo de haber sido redescubierto por Yeats, y con Gerard Manley Hopkins (Moynihan, 1968: 25). En cuanto a Blake, consideraba que su obra estaba muy por encima de lo que él podía aspirar a crear. Una de las cualidades que más admiraba en él era su dogmatismo (Moynihan, 1968: 36). Thomas creía que todo verdadero poeta debía ser dogmático, y esto se nota con claridad en sus primeros poemas, en los cuales recurre a un tono autoritario, casi profético, que no permite cuestionamientos. En cambio se sentía mucho más cercano a Hopkins, con quien comparte una profunda preocupación por el aspecto sonoro de la poesía, no sólo en los versos aliterativos propios de la antigua poesía inglesa y rescatados por Hopkins, sino también las asonancias, consonancias, rimas internas, palabras compuestas y sustantivos profusamente calificados con otros sustantivos o verbos adjetivados. Por añadidura, tanto Hopkins como Thomas procuraron imprimir gran fuerza espiritual a su poesía.

Hay otro factor determinante para apreciar la poesía de Dylan Thomas, y es el hecho de que era un maravilloso lector e intérprete. Las dotes histriónicas de Thomas cautivaron a innumerables auditorios y contribuyeron en gran medida a su popularización. De joven había sido actor aficionado; ya en Londres, hay registros en los diarios de sus amigos de que a menudo era el centro de atención en las fiestas. A juzgar por las abundantes grabaciones que se conservan, Thomas tenía una voz privilegiada. Sabía envolver al auditorio y cautivarlo con la magia de su palabra. Fue precisamente a raíz de estas lecturas que se volvió tan popular en Estados Unidos, lo cual le proporcionaría un refrendo más en su pasaporte a la fama. Thomas no sólo leía poemas suyos en el radio, sino también poemas de otros autores; conforme se fue asentando su reputación, lo invitaban a simples charlas, entrevistas o conferencias donde hacía alarde de sus habilidades vocales.

Pocos entre sus escuchas lograban entender el significado preciso de su poesía; es más probable que la mayoría no acertara a decir cuál era la razón por la cual su obra resultaba tan atractiva y estremecedora. Esto, lejos de ser un punto en su contra, nos revela que su poesía funciona a otro nivel, a un nivel acaso visceral, que, en sus mejores expresiones, revela una verdadera maestría en el arte de conmover. Ahora bien, el estereotipo del galés es el del hombre apasionado e irreflexivo, opuesto al flemático 
pueblo inglés. De hecho, un influyente crítico, Karl Shapiro, afirma que Dylan Thomas resistió el tradicionalismo intelectual de la escuela de Eliot; que de hecho la poesía de Thomas nace de la bancarrota de la tradición de Yeats, Pound y Eliot, y que constituye una protesta en contra de la poesía libresca de Auden (Cox, 1987: 171).

Sin embargo, la intensidad y el vigor de la poesía de Thomas no son el producto de una emoción irreflexiva y fuera de control. Detrás de cada uno de sus poemas hay un meticuloso cuidado de la forma, así como un arduo trabajo de pulimiento y perfección rítmica. Los metros de Thomas, con frecuencia inventados por él mismo, están cuidadosamente medidos. Casi nunca utiliza el verso libre. Incluso, en muchos casos, el ritmo pareciera tener más significado que el contenido.

Los primeros poemas de Dylan Thomas tienen tres temas principales: los sueños de génesis, la labor del poeta y el ciclo vital. Al hablar de sueños de génesis tomo los términos del poema "I Dreamed My Genesis", pero el tema se repite en poemas tan memorables como "I Fellowed Sleep", "When Once the Twilight Locks No Longer", "Before I Knocked", "From Love's First Fever to Her Plague" y "The Seed at Zero". A Thomas le obsesionaba tanto el momento de la concepción del ser humano, que algunos de sus poemas son verdaderas exploraciones poético-científico-mitológicas de este momento. El primer paso es el sueño, estado ideal para que la conciencia se expanda, abandonando momentáneamente las limitaciones del cuerpo. Ésta es la primera estrofa de "I Fellowed Sleep".

I fellowed sleep who kissed me in the brain,

Let fall the tear of time; the sleeper's eye.

Shifting to light, turned on me like a moon.

So, planing-heeled, I flew along my man

And dropped on dreaming and the upward sky. ${ }^{2}$

Traduzco libremente:

El sueño, mi compañero, me besó en el seso,

Y cayó la lágrima del tiempo, el ojo del durmiente.

Cambié a la luz, y se encendió en mí como una luna.

Así, planeando en talones, volé junto a mi hombre

Y caí en el sueño y en el cielo hacia arriba.

El beso del sueño es el beso de Morfeo que adormece al cerebro dejando que la conciencia ascienda, guiada por la luz que se enciende como una luna. Los talones alados de Mercurio transportan a la conciencia en su viaje. Este poema es como el sueño de Escipión, un sueño de vuelo en el que la voz poética vuela por el éter, abandona la tierra y llega a un lugar más allá de las estrellas donde presencia su pasado inmemorial, donde

2 Todos los poemas aquí citados están tomados de The Collected Poems of Dylan Thomas, 19341952, reeditado por New Directions en 1971. 
nacen los padres de los padres y los ojos de las madres, todos hombres que sueñan, en una fantasía al estilo de "Las ruinas circulares de Borges": "These are but dreaming men. Breathe, and they fade". ["Éstos no son más que hombres soñando. Respira y se esfuman. "] Y más adelante: "I blew the dreaming fellows to their bed / Where they still sleep unknowing of their ghost". ["Soplé a los soñadores y cayeron en su lecho, donde aún duermen, ignorantes de su espíritu".] La historia y la visión se conjugan; el poema asciende hasta el clímax de la penúltima estrofa y el pausado desenlace del final:

Then all the matter of the living air

Raised up a voice, and, climbing on the words,

I spelt my vision with a hand and hair,

How light the sleeping on this soily star,

How deep the waking in the worlded clouds.

There grows the hours' ladder to the sun,

Each rung a love or losing to the last,

The inches monkeyed by the blood of man.

An old, mad man still climbing in his ghost,

My fathers' ghost is climbing in the rain.

[Y toda la sustancia del aire viviente

Elevó su voz, y, trepando por el verbo,

Recité la visión con mano y pelo:

Qué ligero el sueño de la estrella sucia,

Qué hondo despertar en las pobladas nubes.

Ahí crece la escalera de horas hasta el cielo,

Cada peldaño, un amor, o perdiendo hasta el final,

Las pulgadas simiescas de la sangre humana.

Un anciano demente aún trepa en su fantasma.

El fantasma de mis padres trepa bajo la lluvia.]

Sin embargo, el viaje de la conciencia no es sólo un acto espiritual, sino que tiene una importante dimensión física. En "I Dreamed my Genesis" se nota claramente el vigor físico de las palabras mismas, que conjuga sonido y significado. La conciencia se desprende de la carne, y lo hace taladrando, traspasando el "nervio ceñido" del cuerpo y rompiendo el cascarón de la tierra que gira.

I dreamed my genesis in sweat of sleep, breaking

Through the rotating shell, strong

As motor on the drill, driving

Through vision and the girdered nerve.

From limbs that had the measure of the worm, shuffled

Off from the creasing flesh, filed 
Through all the irons in the grass, metal

Of suns in the man-melting night.

[Soñé mi génesis sudando, irrumpiendo

A través del cascarón que gira, fuerte

Como el motor del taladro, perforando

La visión y el nervio ceñido.

Los miembros del tamaño de un gusano, me libré

De los pliegues de la carne y limé

Todos los hierros de la hierba, el metal

De los soles en la noche que derrite humanos. ]

En estos dos poemas se encuentra la imagen de la escala de Jacob, la escalera simbólica que representa el eslabón que une a la conciencia con su origen. Otra manera de representar este eslabón es una puerta — reminiscente de algunos cuadros surrealistas - que separa al estado de vigilia del estado de ensoñación, lo mismo que al estado de la vida del de la muerte. Para Thomas, el crepúsculo, la transición entre noche y día, es la puerta que encierra el secreto de la vida y la muerte, de lo corpóreo y lo incorpóreo. Cuando la puerta crepuscular se abre, la conciencia se libera y se expande, como se observa en "When Once the Twilight Locks No Longer":

When once the twilight screws were turned,

And mother milk was stiff as sand,

I sent my own ambassador to light.

[Cuando giraron las bisagras del ocaso

Y la leche materna se secó como la arena,

Envié a la luz a un ser con mi embajada. ]

Dylan Thomas estaba muy consciente de sí mismo como "creador" de poemas, como forjador de versos, y hasta cierto punto, como bardo o mago de las palabras. Esta exaltación de la función del poeta se deriva en cierta medida de la tradición galesa, porque en la antigüedad galesa un bardo no era sólo un poeta profesional, sino que se reconocía que poseía poderes espirituales extraordinarios. Un crítico galés, Gwyn Williams, habla de la importancia de la aliteración para la poesía galesa. Utiliza el término cynghanedd, que significa armonía, y que es un medio para crear versos con sonidos repetidos. Thomas lo utiliza constantemente ${ }^{3}$ (Ferris, 1978: 115).

3 Cabe aclarar que el cynghanedd no es sólo una aliteración con nombre pintoresco, sino que se refiere a la repetición de un sonido sin importar si se encuentra al principio de una palabra o no. Incluye tanto aliteraciones como rimas internas, y es un recurso al que se adhiere estrictamente la poesía tradicional de Gales. A Guide to Welsh, Cornish and Breton Verse en http: //www. kemewegva. com/ PDFs/Cynghanedd. pdf 
Asimismo, Thomas frecuentemente escribe poemas autorreferentes, es decir, poemas acerca de la composición poética. El tiempo que le dedica es para él un tiempo querido por los frutos que trae consigo, pero también es un tiempo demente, chiflado, porque es cuando el poeta se desprende de las limitaciones de la razón y se esfuerza por ver lo infinito de las cosas. La página en blanco le otorga la posibilidad de crear cualquier cosa que su fantasía requiera, y él se desahoga en ella como en una amante. Tal es el caso de este pasaje de "My Hero Bares His Nerves" en el que se expresa una dimension del acto de escribir en la que se mezclan erotismo y consuelo.

\author{
And these poor nerves so wired to the skull \\ Ache on the lovelorn paper \\ I hug to love with my unruly scrawl \\ That utters all love hunger \\ And tells the page the empty ill. \\ [Y estos pobres nervios, cableados al cerebro, \\ Se duelen en el cuaderno enamorado \\ Que siempre abrazo con mis garabatos, \\ Que pronuncian el hambre amorosa \\ Y le cuenta a la página este vacuo malestar.]
}

Los poemas que tratan del ciclo vital son posiblemente los más sonoros y memorables de Thomas. En los dos temas antes presentados, los sueños de génesis y la labor del poeta, Dylan explora los misterios del origen de la vida y de la creación poética. Un narrador en primera persona protagoniza estas expediciones. Es la voz de la conciencia en el ser antes de su concepción y cuando ésta es muy reciente, y es también la voz del poeta que descubre su vocación y se maravilla de encontrar poesía en todo lo que le rodea.

Ahora bien, en los poemas del ciclo vital se distingue una voz más poderosa y resonante, una voz casi titánica que, a pesar de pertenecer al mundo finito, evoca el infinito con ritmos sonoros. Son poemas contundentes y deslumbradores, tanto que con ellos llamó Thomas la atención de sus contemporáneos. Muy a la manera de Blake por lo cósmico de sus alcances, estos poemas no por destellantes carecen de contenido. La conciencia, curiosa, forma parte de un ciclo vital; al encamar, descubre la dualidad. La caída de Adán y Eva y su expulsión del Paraíso se derivó del descubrimiento de la diferencia, es decir, de la dualidad. Así, hay hermosas coincidencias entre la poesía de Blake y la de Thomas. Donde Blake escribe: "Eternity is in love with the productions of time", Thomas explica en "Before I Knocked": "I who was rich was made the richer / By sipping at the vine of days". ["Yo que era rico, me volví más rico / al sorber de la viña de los días".]

En un primer momento se tiende a agrupar en dos bloques rígidos a los símbolos de la vida y a los de la muerte con sus respectivos encabezados. De esta manera, por ejemplo, el color verde, la primavera y la juventud serían parte del bloque de la vida, y el gusano, la tumba y el vacío, del de la muerte. Pero los poemas de Thomas tienen la 
cualidad del movimiento. Para analizar esta cualidad resulta revelador observar cómo explicaba su manera de componer:

\begin{abstract}
Un poema mío necesita huestes de imágenes porque su centro son estas huestes de imágenes. Hago una imagen [...] o mejor dicho permito que una imagen se haga en mí emocionalmente, y luego le aplico cualesquiera fuerzas intelectuales y críticas, para que a su vez genere otra imagen que contradiga a la primera; luego hago que nazca una tercera imagen al combinar las dos primeras... Cada imagen contiene las semillas de su propia destrucción, y mi método dialéctico es un constante construir y destruir imágenes nacidas de la semilla central. A partir del conflicto inevitable de imágenes, trato de hacer esa paz momentánea que es el poema (Moynihan, 1968: 100-101. Mi traducción).
\end{abstract}

La sucesión de imágenes contradictorias lleva al entendimiento de un extremo a otro del concepto de manera violenta. Así, los símbolos parecen indicar lo opuesto de lo que convencionalmente significan. Esto es lo que ocurre en estos famosos versos de "The Force That Through The Green Fuse":

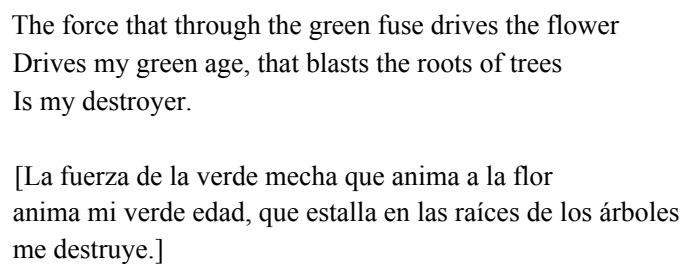

La fuerza de la vida y el crecimiento es la misma que conduce a la muerte. El tallo verde que sostiene a la flor es la mecha de la bomba que finalmente la hará estallar y morir. Lo mismo sucede con la primavera en "I in my Intricate Image": "Beginning with doom in the bulb, the spring unravels". ["Empezando por el bulbo condenado, se despliega la primavera".] El bulbo donde nacen la planta y la flor está condenado a muerte; y, claro, si extendemos la metáfora un poco más, la muerte del bulbo es el origen de la primavera, pues al abrirse, al romperse, nacen de él el tallo y la flor. Esta imagen es muy parecida a la célebre de Eliot, "April is the cruellest month / Breeding lilacs out of the dead trees". ["Abril es el mes más cruel, pues saca lirios del árbol muerto".] Sin embargo, el efecto de close up y cámara lenta es mucho más poderoso en Thomas. Es también el mismo tema que la mitología griega explica con el matrimonio de Cora y Hades. Hija de Deméter, diosa de la cosecha, Cora simboliza la semilla que se entierra y se desintegra para dar nueva vida cada año.

Thomas era capaz de conjugar un registro científico y un universo mitológico con una compresión asombrosa. Y es a través de los verbos y los ritmos abruptos que logra uno de sus mejores poemas, "Light Breaks Where No Sun Shines". 
Light breaks where no sun shines;

Where no sea runs, the waters of the heart

Push in their tides;

And, broken ghosts with glow-worms in their heads,

The things of light

File through the flesh where no flesh decks the bones.

[La luz irrumpe donde el sol no brilla;

Donde no hay mar, las aguas del corazón

Empujan sus mareas;

Y así, fantasmas rotos, con luciérnagas en la cabeza,

Cosas de luz,

Recorren la carne donde no hay carne en los huesos.]

Es común que los poemas de Dylan Thomas terminen en una nota alta, con un efecto de elevación. Este poema ejemplifica su manera de conjugar sonido y sentido para lograr dicho efecto. No hay nada parecido a una trama narrativa, no hay ninguna historia que pueda rastrearse en él. Sólo hay una repetición insistente de elementos antitéticos que entran en contacto en un lugar específico. En cada estrofa hay un choque de contrarios, un choque físico y trabajoso que sólo se trasciende en la última estrofa. Esta gradación de lo físico a lo espiritual se logra a través de la repetición y los ecos sonoros. Al estilo de los antiguos bardos, Thomas construye hechizos y encantamientos cuyo significado yace en el performance mismo de la poesía, más allá de la página impresa. Su musicalidad exige ser declamada.

Tal es el caso de uno de los mejores poemas de Thomas, "Especially When the October Wind", escrito con motivo de su cumpleaños. El tono no es titánico ni sentencioso; se escucha una voz más modesta, en tono de confesión. Sugiere además un muy sutil hilo narrativo que permite imaginar una acción concreta: el poeta sale a caminar a la orilla del mar y medita sobre el mundo que lo rodea. Los objetos de la naturaleza que observa se convierten en el sonido que hacen sus nombres en la mente del poeta en un contrapunto rítmico y poético donde se entrelazan dos temas que casi podríamos llamar melódicos. La vehemencia de cada estrofa se incrementa gracias al artificio de la repetición de patrones rítmicos para crear una escalada en ambas musicalidades, que parecen entablar un forcejeo, una lucha amorosa, hasta que una de ellas vence a la otra. Aun cuando sólo la declamación oral del poema puede transmitir con exactitud la naturaleza de este encuentro sonoro, baste por ahora la descripción del efecto para transmitir una idea del modo musical de composición poética de Dylan Thomas. Dylan, que en antiguo galés significa "el hijo de la ola", parece absorber la música de la naturaleza para reproducirla y darle coherencia para el oído humano. Y esto no es cualquier hazaña. 
$94 \square$ DYLAN THOMAS, EL HIJO DE LA OLA

Obras citadas

Burdette, Robert K. 1972. The Saga of Prayer: The Poetry of Dylan Thomas. La Haya / Paris: Mouton.

Cox, C. B. 1987. Dylan Thomas. A Collection of Critical Essays. Nueva Jersey / Londres: Prentice Hall.

FERris, Paul. 1978. Dylan Thomas. Londres: Penguin.

Moynihan, William T. 1968. The Craft and Art of Dylan Thomas. Ithaca: Cornell University Press.

Pratt, Annis. 1970. Dylan Thomas' Early Prose: A Study in Creative Mythology.

Pittsburgh: University of Pittsburgh Press.

Thomas, Dylan. 1971. The Collected Poems of Dylan Thomas, 1934-1952. Nueva York: New Directions. 